\title{
Subtalar dislocation in a handball player
}

\author{
K. Bak MD and J. S. S. Koch MD
}

Department of Orthopaedic Surgery, Central Hospital in Nykobing Falster, Denmark

Subtalar dislocation is an uncommon injury ${ }^{1-5}$. Associated fractures involving the talocalcaneal and talonavicular joints are often present. The mechanism of injury is usually a motor vehicle accident, a fall from a height or an inversion stress to the foot ${ }^{1-3,6}$. Medial dislocation is by far the commonest type ${ }^{2,3,6,7}$.

European handball is a popular sport in Denmark and other Scandinavian countries. It is also the sport which has the highest incidence of injuries.

We report a case of a medial subtalar dislocation in a handball player. A possible predisposing factor is discussed.

\section{Case report}

A 20-year-old Dane, an elite handball player, presented with bilateral recurrent ankle sprains and a feeling of giving way which he had suffered for a period of 2 years. The condition had worsened during the previous 6 months and he went to the team physiotherapist for advice. Bilateral instability was found but no preventive treatment was given. The athlete continued to participate in handball at an elitist level.

The athlete was then injured during a second division handball match: he was tackled during a jump, and as he fell he landed with his left foot on the foot of an opponent. At the casualty department he was found to have a medial subtalar dislocation with associated minor subtalar avulsions (Figure 1); there was no sign of neurovascular damage. After reduction under general anaesthesia, the ankle was immobilized in a plaster cast for 8 weeks.

\section{Discussion}

A subtalar dislocation is rarely seen in sports, though Grantham ${ }^{7}$ reported five cases of subtalar dislocations, of which four had occurred in basketball players. He therefore termed the injury 'the basketball foot'.

Complications such as neurovascular damage, joint stiffness, avascular necrosis of the talus and subtalar arthrosis are seen with varying frequency, depending on the type of injury and the presence of an associated fracture ${ }^{1-7}$. Christensen et al. ${ }^{2}$ reported

Address for correspondence: Klaus Bak MD, Havrevaenget 7, DK4700 Naestved, Denmark

(C) 1991 Butterworth-Heinemann Ltd.

0306-3674/91/010024-02

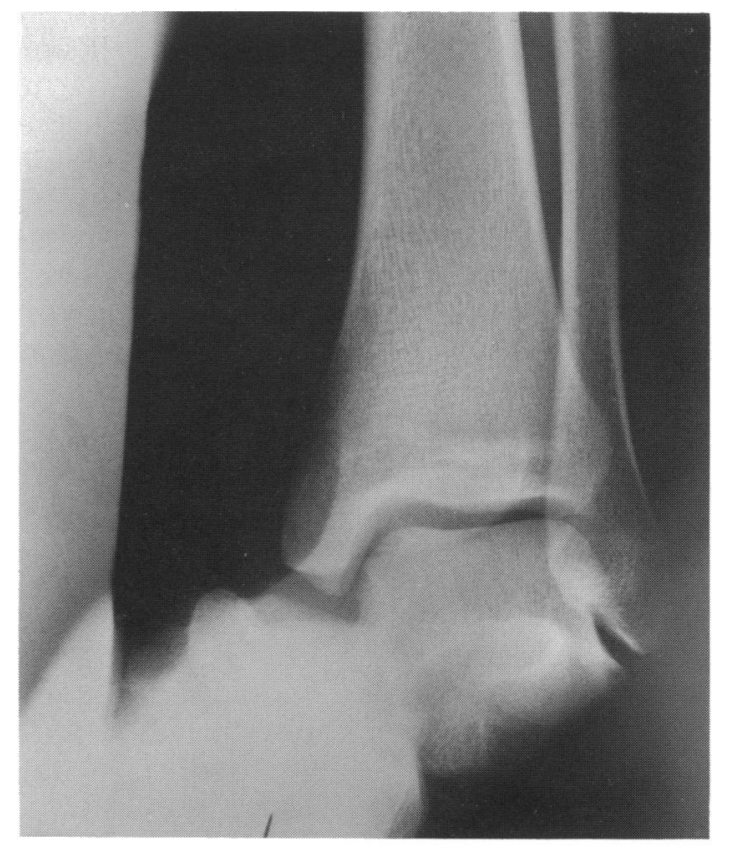

a

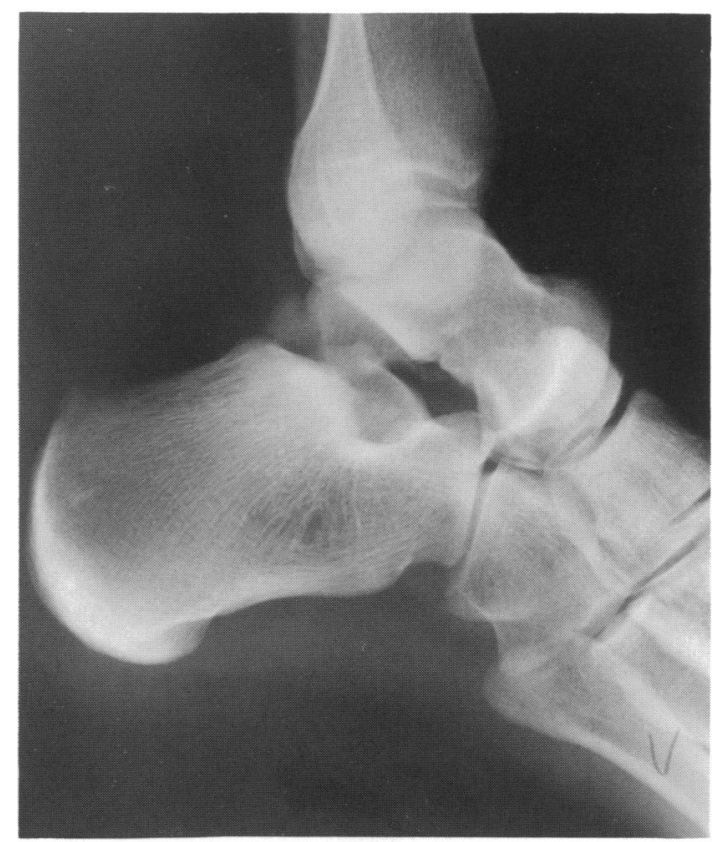

b

Figure 1a and b. Anteroposterior and lateral views of the ankle showing medial subtalar dislocation with minor avulsions 
development of subtalar arthrosis in all cases with associated fractures. Complications seem to be more frequent in compound injuries ${ }^{2,3}$ and less frequent in simple inversion injuries ${ }^{1,3,7}$.

In most team sports, such as football and handball, injuries to the ankle are very common ${ }^{8}$. The commonest residual disability has been termed 'functional instability', that is recurrent sprains and/or a feeling of giving way of the ankle $e^{9,10}$. Since patients with functional instability not only suffer from a mechanical instability but also from a diminished postural control, it seems obvious that this may predispose to more serious injuries as occurred in our case.

Ankle disk (a 'wobble board') training has been found not only to improve the feeling of giving way as well as postural control and pronator muscle strength $^{11}$ but also to reduce the incidence of ankle sprains $^{12}$. The authors suggest that preventive measures such as ankle disk training should be obligatory in athletes suffering from functional instability of the ankle.

\section{References}

1 Buckingham WW. Subtalar dislocation of the foot. J Trauma 1973; 13: 753-65.

2 Christensen SB, Lorentzen JE, Krogsoe $\mathrm{O}$ et al. Subtalar dislocation. Acta Orthop Scand 1977; 48: 707-11.

3 DeLee JC, Curtis R. Subtalar dislocation of the foot. I Bone Joint Surg [Am] 1982; 64-A: 433-7.

4 Mattingly DA, Stern PJ. Bilateral subtalar dislocations. Clin Orthop 1983; 177: 122-4.

5 Ritsema GH, Vosmer AM. Traumatic subtalar dislocation and fracture dislocation. Ned Tijdschr Geneeskd 1987; 131: 358-61.

6 Monson ST, Ryan JR. Subtalar dislocation. J Bone Joint Surg [Am] 1981; 63-A: 1156-8.

7 Grantham SA. Medial subtalar dislocation: five cases with a common etiology. J Trauma 1964; 4: 845-9.

8 Jorgensen U. Epidemiology of injuries in typical Scandinavian team sports. Br J Sports Med 1984; 18: 59-63.

9 Freeman MAR, Dean MER, Hanham IMF. The etiology and prevention of functional instability of the foot. J Bone Joint Surg [Br] 1965; 47-B: 678-85.

10 Staples OS. Ruptures of the fibular collateral ligaments of the ankle. J Bone Joint Surg [Am] 1975; 57-A: 101-7.

11 Tropp H. Functional instability of the ankle joint. Linköping University Medical Dissertations No. 202, 1985.

12 Tropp H, Askling C, Gilquist J. Prevention of ankle sprains. Am J Sports Med 1985; 13: 259-62. 